\title{
The Application of Acrylic Acid as Precipitation Inhibitor for ASP Flooding
}

Khaled Abdalla Elraies* and Shuaib Ahmed Kalwar

Faculty of Geoscience and Petroleum Engineering. Petroleum Engineering Department, Universiti Teknologi Petronas, Malaysia

\begin{abstract}
Alkaline-Surfactant-Polymer (ASP) flooding has shown incredible successes for enhancing oil recovery for both sandstone and carbonate reservoirs. However, the main constraint of ASP flooding in carbonate reservoirs is the presence of undesired minerals either within the reservoir rock or reservoir brine. These minerals could react with the added chemicals to form their insoluble salts as precipitations. In this paper, the performance of the acrylic acid was evaluated in the presence of sodium metaborate as an alkaline, alpha olefin sulfonate as a surfactant and AN$125 \mathrm{SH}$ as a polymer. The effect of various acrylic acid concentrations on alkalinity, interfacial tension reduction and polymer viscosity were investigated using hard brine with a total salinity of 59,940 ppm. Fluid-fluid compatibility test indicates that acrylic acid has the potential to prevent any precipitation when hard brine is used. The acrylic acid to alkali ratio of $0.6: 1$ was found to be the optimum ratio for keeping the solution without precipitations for 30 days at $80^{\circ} \mathrm{C}$. It was also observed that the combination of ASP with acrylic acid has a positive effect on interfacial tension and solution viscosity. This makes the new system more flexible for offshore application in which hard brine or sea water could be used to prepare ASP slug without any negative effects.
\end{abstract}

\section{Introduction}

Alkali-surfactant-polymer (ASP) flooding has been proven as the most effective and easiest method in sandstone reservoirs $[1,2]$. The successful results in sandstone formation have widened this method to carbonate reservoirs as well [3]. It is found that about $60 \%$ of the world's oil reserves and $40 \%$ of the world's gas reserves exist in carbonate rocks [4]. Having been potentially attractive, these rocks exhibit immense variation in properties that include porosity, permeability, and flow mechanism. These rocks can be naturally fractured and preferentially oil-wet $[4,5]$. In addition, carbonate formations contain large amounts of calcium and magnesium ions in the form of calcite $\left(\mathrm{CaCO}_{3}\right)$ and dolomite. These rocks also have small quantities of calcium sulphate minerals that are anhydrite and gypsum $[4,6]$. The main constraint of ASP flooding in carbonate reservoir is the formation of precipitation. Alkali reacts with divalent cationic minerals, resulting in an insoluble salts known as precipitations. These precipitates can cause significant formation damage and pore plugging in the reservoir formation [6].

The purpose of ASP flooding is to increase oil production by reducing the residual oil saturation after waterflooding [7]. For the displacement of oil in the porous media and reducing the capillaries of petroleum reservoir rocks, it is necessary to reduced interfacial tension between oil and ASP slug to an ultra-low interfacial tension [8]. Mobility control is also one of the most important mechanisms for oil recovery with respect to ASP flooding [9]. Many papers focus on the study of interfacial tension and mobility control for the purpose of practical applications.

In this paper, alkaline-surfactant-polymer formulation was developed by incorporating acrylic acid to form in-situ inhibitor to overcome the precipitation problems caused by reservoir minerals and brine compositions. Acrylic acid has the ability to react with sodium ions present in the brine to forms sodium acrylate. The produced sodium acrylate accumulates on surfaces of the divalent cations (calcium and magnesium ions) to prevent them from precipitating [10]. Sodium metaborate was blended as an alkali with acid to generate more acrylate. Sodium metaborate is a novel alkali that has high capability to tolerate multivalent ions. Its borate ion reacts with these cationic minerals and forms amorphous crystals that are effectively dissolvable in aqueous solution [11]. When acrylic acid and sodium metaborate were mixed in the presence of synthetic hard brine, the combination works more effectively to sequester these minerals from any precipitation [12]. The main advantage of this combination involves the use of hard brine without the need of softening the injection water for ASP flooding application.

\section{Experimnetal Methodology}

\section{Materials description}

Crude oil used in this study, was collected from Dulang oil field, Malaysia. The density of the crude oil was $0.799 \mathrm{~g} / \mathrm{cc}\left(80^{\circ} \mathrm{C}\right)$ and the API gravity was $35.5^{\circ} \mathrm{C}$. The crude oil viscosity is $0.96 \mathrm{cp}$ at $80^{\circ} \mathrm{C}$.

Sodium metaborate was supplied by Rio Tinto Minerals. Acrylic acid was supplied by Sigma Aldrich. $\mathrm{C}_{20-24}$ Alpha Olefin Sulfonate (AOS) was supplied by Stepan Chemical Co. AN-125 SH copolymer was supplied by SNF Floerger. Synthetic hard brine with a total salinity of 59,940 ppm was used to prepare all solutions and main compositions of the hard brine are given in Table 1 .

\section{Apparatus and Methods}

\section{Fluid-fluid compatibility test}

The first step for this test was to prepare samples of various sodium metaborate concentrations using the synthetic brine. Purpose of this test was to evaluate the compatibility of the sodium metaborate with the brine. Next, the compatibility of different acrylic acid to alkali weigh ratios was performed. The aim of this test was to find an optimum ratio,

*Corresponding author: Khaled Abdalla Elraies, Faculty of Geoscience and Petroleum Engineering. Petroleum Engineering Department, Universiti Teknologi Petronas, Malaysia, Tel: +605 368 7037; Fax: +605 365 5670; E-mail: khaled.elraies@petronas.com.my, alrayes2006@yahoo.co.uk

Received April 01, 2013; Accepted May 24, 2013; Published June 01, 2013

Citation: Elraies KA, Kalwar SA (2013) The Application of Acrylic Acid as Precipitation Inhibitor for ASP Flooding. J Pet Environ Biotechnol 4: 141. doi:10.4172/2157-7463.1000141

Copyright: ( $) 2013$ Elraies KA, et al. This is an open-access article distributed under the terms of the Creative Commons Attribution License, which permits unrestricted use, distribution, and reproduction in any medium, provided the original author and source are credited. 
Citation: Elraies KA, Kalwar SA (2013) The Application of Acrylic Acid as Precipitation Inhibitor for ASP Flooding. J Pet Environ Biotechnol 4: 141. doi:10.4172/2157-7463.1000141

\begin{tabular}{|c|c|}
\hline Components & Concentration \\
\hline Sodium, ppm & 20,445 \\
\hline Calcium, ppm & 2523 \\
\hline Magnesium, ppm & 239 \\
\hline Chloride, ppm & 36,733 \\
\hline
\end{tabular}

Table 1: Composition of synthetic hard brine.

at which no precipitation exists. In the third step, samples of surfactant and polymer with and without acid-alkali were prepared in order to investigate the compatibility of surfactant and polymer with the hard brine. All the compatibility tests were conducted at $80^{\circ} \mathrm{C}$ for a period of time and observation were made by visual evaluation with the formation of solids being indicative of incompatible fluids

\section{Interfacial tension test}

Interfacial Tension (IFT) between Dulang crude oil and various solutions were measured by spinning drop method. Model SVT 20 spinning drop tensiometer equipped with video camera was utilized to determine the IFT at $80^{\circ} \mathrm{C}$ using hard brine.

\section{Viscosity measurement test}

A polymer stock solution with $5000 \mathrm{ppm}$ of AN-125 SH was prepared with deionised water. The stock solutions were mixed slowly with a magnetic stirrer for 1 to 2 days to properly hydrate the dry powdered polymer. Stock solutions were then filtered with $1.2 \mu \mathrm{m}$ filter paper using OFIT model filter press under a constant pressure of 15 psig. The solutions were collected in a graduated cylinder, and the time was recorded after every $10 \mathrm{ml}$ collected. The collected data from filtration was then used to calculate filtration ratio by using equation 1 . A filtration ratio less than 1.2 is considered excellent.

$$
\text { Filtration }_{\text {ratio }}=\frac{\Delta t_{80-100 m l}}{\Delta t_{20-40 m l}}
$$

Where $\Delta t_{20-40 \mathrm{ml}}$ is the time to filter equal volumes of polymer solution near the beginning (20 to $40 \mathrm{ml}$ ) and $\Delta t_{20-40 \mathrm{ml}}$ is the time to filter equal volumes of polymer solution near the end $(80-100 \mathrm{ml})$. High pressure high temperature Viscometer (OFIT 1100 model) was then used to determine the polymer viscosity at different shear rates. All viscosity measurements were performed at $80^{\circ} \mathrm{C}$.

\section{Results and Discussions}

\section{Alkali-brine interaction}

The sodium metaborate employed in this study was incompatible with the synthetic hard brine. Although, sodium metaborate showed some resistance against water hardness at the ambient temperature, precipitations were formed immediately at $80^{\circ} \mathrm{C}$. This is attributed to the interaction of bicarbonate group with divalent metal cations to form precipitates of carbonates. Magnesium hydroxide can also be generated to for precipitations at high $\mathrm{pH}$. Table 2 shows the results of incompatibility of sodium metaborate with different concentrations ranging from $0.2 \%$ to $1.0 \mathrm{wt} \%$ during 15 at $80^{\circ} \mathrm{C}$

\section{Acrylic acid and alkali interaction}

Based on the previous compatibility test, sodium metaborate was not compatible with the synthetic brine. Hence, the alkali and acrylic acid were combined with the brine to form in-situ inhibitor and to keep the solutions clear without any precipitations. Different acrylic acid to alkali weight ratios was screened to evaluate the performance of the in- situ precipitation inhibitor at $80^{\circ} \mathrm{C}$. Table 3 summarizes the results for different acid to alkali weight ratio using sodium metaborate.

The performance of in-situ inhibitor was very effective in preventing $\mathrm{Ca}^{++}$and $\mathrm{Mg}^{++}$precipitations over time. Figure 1 shows the compatibility of different acid-alkali weight ratios after 30 days at $80^{\circ} \mathrm{C}$. It was also observed that the efficiency of the inhibitor increased as the acid to sodium metaborate weight ratio was increased. For instance, with a small acid to alkali weight ratio, the produced inhibitor (sodium acrylate) was insufficient to prevent the precipitations. All the acid was neutralized by the added alkali and sodium ions present in the brine. However, when a high acid to alkali weight ratio was used, only the required amount of acid was neutralized by the added alkali. The inhibitor adsorbs on the active growth sites of the $\mathrm{Ca}^{++}$and $\mathrm{Mg}^{++}$

\begin{tabular}{|c|c|c|c|c|c|c|c|c|c|c|}
\hline \multirow{2}{*}{ Days } & \multicolumn{10}{|c|}{ Sodium Metaborate wt\% } \\
\cline { 2 - 11 } & 0.2 & 0.3 & 0.4 & 0.5 & 0.6 & 0.7 & 0.8 & 0.9 & 1.0 \\
\cline { 2 - 10 } & \multicolumn{7}{|c|}{$\mathrm{pH}$} \\
\cline { 2 - 11 } & 8.96 & 8.94 & 9.15 & 9.18 & 9.23 & 9.38 & 9.72 & 9.98 & 10.19 \\
\hline 0 & $c l o$ & $c l o$ & $c l o$ & $c l o$ & $c l o$ & $p p t$ & $p p t$ & $p p t$ & $p p t$ \\
\hline 1 & $p p t$ & $P p t$ & $p p t$ & $p p t$ & $p p t$ & $p p t$ & $p p t$ & $p p t$ & $p p t$ \\
\hline 5 & $p p t$ & $P p t$ & $p p t$ & $p p t$ & $p p t$ & $p p t$ & $p p t$ & $p p t$ & $p p t$ \\
\hline 10 & $p p t$ & $P p t$ & $p p t$ & $p p t$ & $p p t$ & $p p t$ & $p p t$ & $p p t$ & $p p t$ \\
\hline 15 & $p p t$ & $P p t$ & $p p t$ & $p p t$ & $p p t$ & $p p t$ & $p p t$ & $p p t$ & $p p t$ \\
\hline
\end{tabular}

Table 2: Occurrences of precipitation by sodium metaborate during 15 days at $80^{\circ} \mathrm{C}$.

\begin{tabular}{|c|c|c|c|c|c|c|}
\hline \multirow{3}{*}{ Days } & \multicolumn{7}{|c|}{ Sodium Metaborate, 1 wt\% } \\
\cline { 2 - 8 } & \multicolumn{7}{|c|}{ Acrylic Acid, wt\% } \\
\cline { 2 - 8 } & 0.2 & 0.3 & 0.4 & 0.5 & 0.6 & 0.7 \\
\cline { 2 - 8 } & \multicolumn{7}{|c|}{$\mathrm{pH}$} & -0.09 \\
\cline { 2 - 8 } & 9.59 & 8.94 & 8.40 & 7.61 & - & - \\
\hline 1 & $c l d$ & - & - & - & - & - \\
\hline 5 & - & - & - & - & - & - \\
\hline 10 & $p p t$ & $p p t$ & $p p t$ & $p p t$ & - & - \\
\hline 20 & $p p t$ & $p p t$ & $p p t$ & $p p t$ & $p p t$ & - \\
\hline 30 & $p p t$ & $p p t$ & $p p t$ & $p p t$ & - \\
\hline
\end{tabular}

ppt denotes precipitation, - denotes clear solution, cld denotes cloudy

Table 3: Summary of the acid-alkali compatibility test during 30 days at $80^{\circ} \mathrm{C}$.

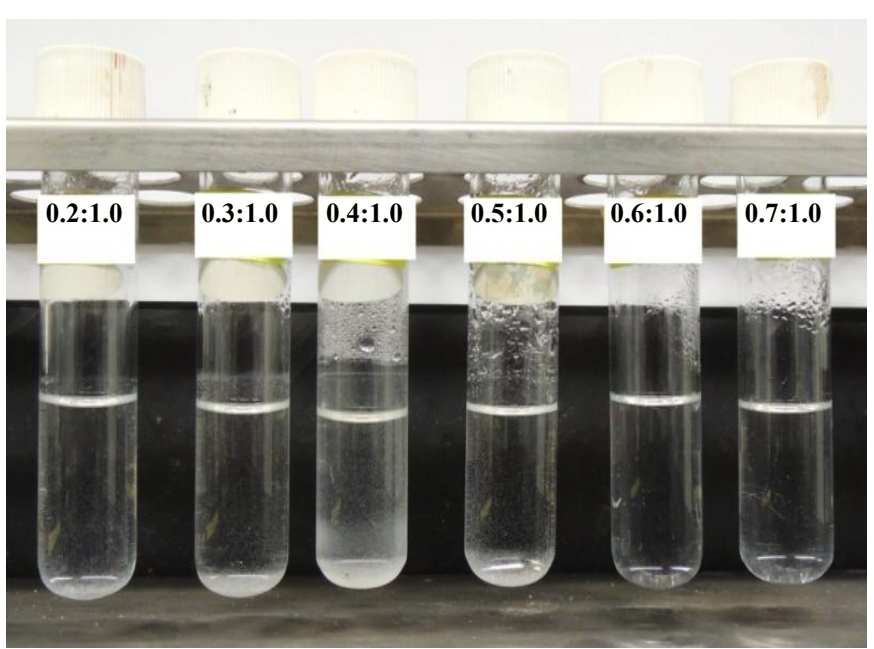

Figure 1: Performance of the in-situ inhibitor for preventing precipitation after 30 days at $80^{\circ} \mathrm{C}$. 
Citation: Elraies KA, Kalwar SA (2013) The Application of Acrylic Acid as Precipitation Inhibitor for ASP Flooding. J Pet Environ Biotechnol 4: 141. doi:10.4172/2157-7463.1000141

surfaces to prevent them from precipitating. By considering $\mathrm{pH}$ into account, the acid to alkali weight ratio of $0.6: 1$ was selected as optimum ratio for this case.

\section{Acid-alkali-surfactants-polymer interaction}

The compatibility of the acid-alkali-surfactant-polymer with the hard brine was investigated under different scenarios. AOS surfactant alone was found ineffective with the brine and formed precipitation or cloudiness at ambient temperature. Copolymer AN-125 SH was compatible with the brine and with the blend of acid-alkali-surfactant for 30 days at $80^{\circ} \mathrm{C}$.

The combination of acid-alkali-surfactant-polymer was also found to be very compatible with the hard brine. No precipitations were generated for 30 days at $80^{\circ} \mathrm{C}$. This shows the effectiveness of the insitu inhibitor for creating such environment where all chemicals are blended without incompatibility issues. The results for the compatibility tests including acid-alkali-polymer and acid-alkali-surfactant-polymer are given in Table 4. It should be noted that acid-alkali weight ratio of 0.6:1 was applied whenever alkali is used.

\section{Interfacial tension measurements}

The effect of precipitation inhibitor in the IFT was investigated using different acid-alkali concentrations and $0.8 \%$ surfactant concentration. As shown in Figure 2, the IFT between crude oil and aqueous solution was significantly decreased by the presence of the acid and alkali in the system. When there was no acid and alkali in the system, $0.8 \%$ surfactant concentration reduced the IFT from about $14.9 \mathrm{mN} / \mathrm{m}$ to $0.64 \mathrm{mN} / \mathrm{m}$. More reduction in the IFT was observed as the acid and alkali concentrations were increased to $0.48 \%$ and $0.8 \%$ respectively. Beyond this point, a slight increase in the IFT was detected due to the excess concentration of sodium acrylate. This will cause the salinity to increase, resulting in a subsequence increase in the IFT. Thus, with the presence of $0.8 \%$ surfactant, the optimum concentration for acid and alkali was found as $0.48 \%, 0.8 \%$ respectively. Using the optimum concentrations, interfacial tension can be reduced from 14.9 $\mathrm{mN} / \mathrm{m}$ to $0.401 \mathrm{mN} / \mathrm{m}$

\section{Viscosity measurements}

The effect of salinity and hardness on the shear viscosity of polymer was investigated using $2000 \mathrm{ppm}$ of AN-125 SH with distilled water, soft brine with $5.2 \%$ of $\mathrm{NaCl}$ and hard brine with $5.99 \%$. All measurements were conducted at $80^{\circ} \mathrm{C}$ and the results for all cases are given in Figure 3. It can be seen from the Figure 4 that $\mathrm{NaCl}$ and divalent ions have a minor effect on the polymer. Although, hardness concentrations were extremely high in the hard brine, only a slight reduction in polymer viscosity was observed. This illustrates that the AN-125 SH polymer

\begin{tabular}{|c|c|c|c|c|c|}
\hline \multirow{3}{*}{ Days } & \multicolumn{5}{|c|}{ Polymer AN-125 SH , 2000 ppm } \\
\cline { 2 - 6 } & \multicolumn{5}{|c|}{ Alpha olefin sulfonate, wt\% } \\
\cline { 2 - 6 } & 0.0 & 0.0 & 0.4 & 0.6 & 1.0 \\
\cline { 2 - 6 } & \multicolumn{5}{|c|}{ Acid to alkali concentrations, wt\% } \\
\cline { 2 - 6 } & $0: 0$ & $0.6: 1.0$ & $0.4: 0.7$ & $0.6: 1.0$ & $0.8: 1.3$ \\
\hline 1 & - & - & - & - & - \\
\hline 15 & - & - & - & - & - \\
\hline 30 & - & - & - & - \\
\hline
\end{tabular}

- denotes clear solution

Table 4: Summary of acid-alkali-surfactant-polymer interaction test during 30 days at $80^{\circ} \mathrm{C}$.

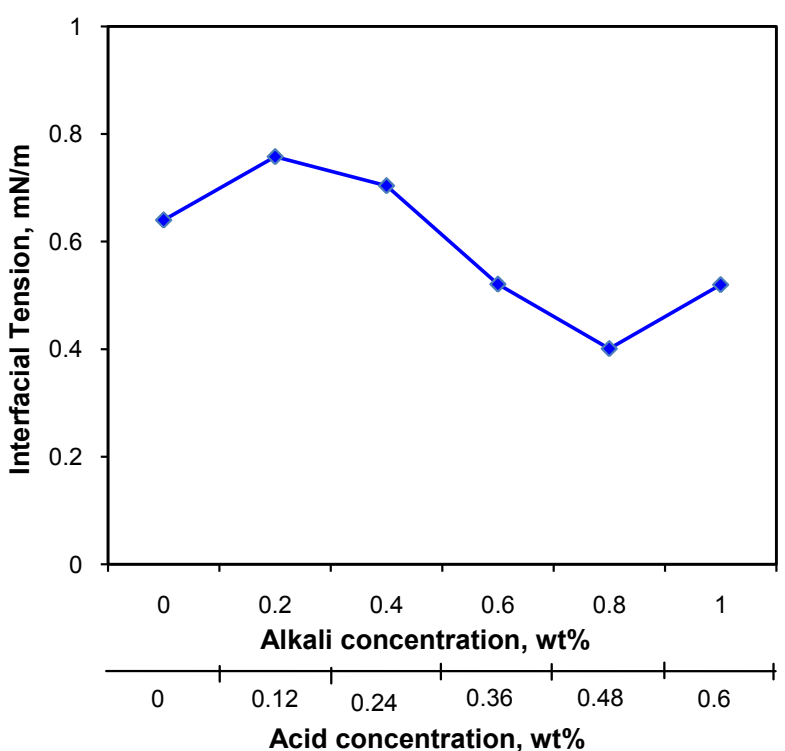

Figure 2: IFT between crude oil and various acid-alkali concentrations in the presence of $0.8 \%$ surfactant.

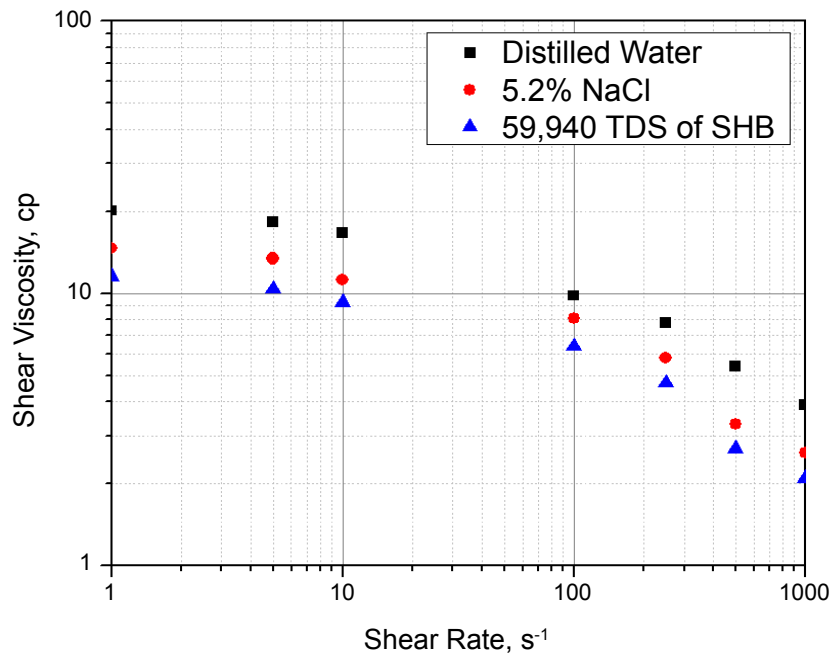

Figure 3: Effect of salinity and hardness on shear viscosity of the polymer.

has high tolerance towards monovalent and divalent ions and is also thermally stable to control viscosity.

Figure 4 shows the impact of various acid-alkali concentrations on the polymer viscosity at $80^{\circ} \mathrm{C}$. All solutions were prepared with the synthetic hard brine using $2000 \mathrm{ppm}$ of polymer. The acid-alkali weight ratio of 0.6:1 was employed for all samples to keep the solutions clear without precipitations. As shown in Figure 4, the polymer viscosity was not affected much by the presence of the different acid and alkali concentrations. For instance, the shear viscosity was $9.3 \mathrm{cp}$ at $10 \mathrm{~s}^{-1}$ shear rates when the sample was prepared by only hard brine while the viscosity was reduced to only $7.6 \mathrm{cp}$ in the presence of $0.12 \%$ and $0.2 \%$ of acid and alkali respectively at the same shear rate. This reduction might be attributed to the presence of alkali and acid. Alkali reduces viscosity because of charge shielding mechanism, while acid decreases $\mathrm{pH}$ which also affects polymer viscosity. 
Citation: Elraies KA, Kalwar SA (2013) The Application of Acrylic Acid as Precipitation Inhibitor for ASP Flooding. J Pet Environ Biotechnol 4: 141. doi:10.4172/2157-7463.1000141

Page 4 of 4

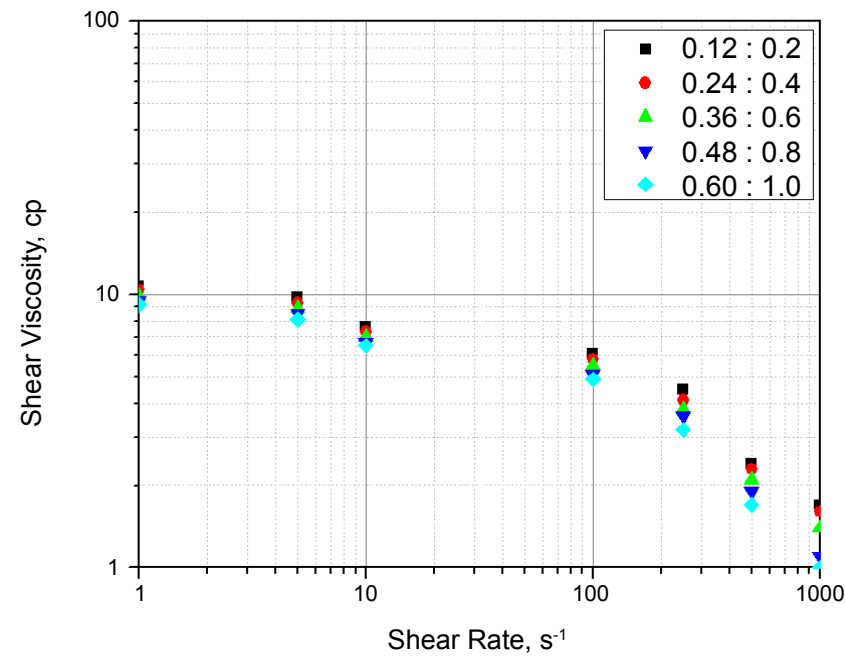

Figure 4: Effect of various acid-alkali concentrations on shear viscosity.

\section{Conclusions}

The present study shows that sodium metaborate and Alpha olefin sulfonate are significantly affected by the presence of divalent metal cations. Precipitations were immediately generated when they are mixed with the hard brine used in this study. However, AN-125 SH copolymer showed excellent properties towards monovalent and divalent ions and no precipitations were seen for 30 days at $80^{\circ} \mathrm{C}$.

The combination of acid and alkali was very effective in preventing any precipitations in the presence of surfactant and polymer. No precipitation was detected for 30 days at $80^{\circ} \mathrm{C}$ when the optimum acidalkali ratio of 0.6:1 was employed. Moreover, the generated in-situ inhibitor has insignificant impact on the interfacial tension and shear viscosity of the polymer.

The benefit of this new system is the use of hard brine instead of softened water while maintaining the desired chemicals activities. Thus, the new acid, alkali, surfactant and polymer AASP formulation can have favourable outcomes and can be cost-effective agent for chemical EOR especially for carbonate reservoirs.

\section{Acknowledgement}

The authors would like to thank the MOR-EOR at Universiti Teknologi PETRONAS for supporting this work. This research work was fully sponsored by YUTP grant no 0153AA-A69. We also thank RIO Tinto Minerals, Stepan Chemical Co. and SNF Floerger for providing some of the materials for this project.

\section{References}

1. Shutang G, Huabin L, Hongfu L (1995) Laboratory Investigation of Combination of Alkaline-Surfactant-Polymer for Daqing EOR.SPE Reservoir Eng 10: 194 197

2. Pratap M, Gauma MS (2004) Field Implementation of Alkaline-SurfactantPolymer (ASP) Flooding : A maiden effort in India. SPE Asia Pacific Oil and Gas Conference and Exhibition, 18-20 October 2004, Perth, Australia.

3. Manrique EJ, Muci VE, Gurfinkel ME (2007) EOR Field Experiences in Carbonate Reservoirs in the United States. SPE Res Eval \& Eng 10: 667-686.

4. Akbar M, Vissapragada B, Alghamdi AH, Allen D, Herron M, et al. (2000) A Snapshot of Carbonate Reservoir Evaluation. Oilfield Rev 12: 20-41.

5. Mahroos FA, Zubari H (2009) Challenges of Producing Middle Eastern Oilfileds During the Maturation Stage- A Paradigm Shift. SPE Middle East Oil and Gas Show and Conference, 15-18 March 2009, Bahrain, Bahrain.

6. Levitt D, Dufour S, Pope G, Morel D, Gauer P (2012) Design of an ASP flood in a High-Temperature, High-Salinity, Low-Permeability Carbonate. International Petroleum Technology Conference, 7-9 February 2012, Bangkok, Thailand.

7. Al-Mjeni R, Arora S, Cherukupalli P, Wunnil, Edwards J, et al. (2010) Has the Time Come for EOR? Oilfield Rev 22: 16-35.

8. Zhao Z, Bi C, Li Z, Qiao W, Cheng L (2006) Interfacial tension between crude oil and decylmethylnaphthalene sulfonate surfactant alkali-free flooding systems. Colloid Surface A 276: 186-191.

9. Lee S, Kim DH, Huh C, Pope GA (2009) Development of a Comprehensive Rheological Property Database for EOR Polymers. SPE Annual Technical Conference and Exhibition, 4-7 October 2009, New Orleans, Louisiana USA.

10. Elraies KA, Tan IM, Awang M, Fathaddin MT (2010) A New Approach to LowCost, High Performance Chemical Flooding System. SPE Production and Operations Conference and Exhibition, 8-10 June 2010, Tunis, Tunisia.

11. Flaaten AK, Nguyen QP, Zhang J, Mohammadi H, Pope GA (2010) Alkaline/ Surfactant/Polymer Chemical Flooding Without the Need for Soft Water. SPE J 15: 184-196.

12. Elraies KA, Ahmed S (2012) A New Strategy for Minimizing Precipitations during ASP Flooding in Carbonate Reservoirs. World Academy of Science, Engineering and Technology 72: 1527-1529. 